\title{
Emphysematous pyelonephritis: a case report
}

\author{
Fabrizio Tiratterra, Ludovica Feigusch, Chiara Villani, Patrizia Marchetti, Umberto Recine \\ Department of Internal Medicine, Santo Spirito Hospital, Rome, Italy
}

\begin{abstract}
Emphysematous pyelonephritis is a severe, life-threatening, necrotizing kidney disease. It occurs almost exclusively in patients with diabetes mellitus. The clinical manifestations are those of pyelonephritis such as dysuria, fever, nausea, vomiting and abdominal pain. The diagnosis is radiological. The treatment strategies are controversial. They include medical management only, percutaneous catheter drainage plus medical management, emergency nephrectomy plus medical treatment or percutaneous drainage plus medical management and emergency nephrectomy. We present the case of a 68-year-old woman affected by emphysematous pyelonephritis successfully managed with conservative medical treatment.
\end{abstract}

\section{Introduction}

Emphysematous pyelonephritis (EPN) is an acute severe necrotizing infection of the renal parenchyma and its surrounding areas, characterized by the presence of gas within the kidney and perinephric tissue. ${ }^{1}$ It occurs almost exclusively in patients with diabetes mellitus. ${ }^{2,3}$ The disease predominantly affects women. Escherichia coli is the causative bacterial source in approximately $70 \%$ of the cases, with Klebsiella, Candida and Pseudomonas species less frequently isolated. ${ }^{4,5}$ Gas formation in EPN is due to pathogenic bacteria causing mixed acid fermentation in a hyper-

Correspondence: Fabrizio Tiratterra, Department of Internal Medicine, Santo Spirito Hospital, Lungotevere in Sassia, 00100 Rome, Italy.

Tel.: +39.06.68352142 - Fax: +39.06.68352137.

E-mail: f.tiratterra@virgilio.it

Key words: Diabetes mellitus; emphysematous pyelonephritis; urinary tract infection.

Contributions: $\mathrm{LF}, \mathrm{CV}$, manuscript drawing up and literature review; UR, PM, clinical management of the case; FT, clinical management of the case and manuscript drawing.

Conflict of interest: the authors declare no potential conflict of interest.

Received for publication: 19 October 2014

Revision received: 22 December 2014.

Accepted for publication: 4 January 2015.

This work is licensed under a Creative Commons Attribution NonCommercial 3.0 License (CC BY-NC 3.0).

(C) Copyright F. Tiratterra et al., 2015

Licensee PAGEPress, Italy

Italian Journal of Medicine 2015; 9:370-372

doi:10.4081/itjm.2015.553 glycemic environment in tissues that are ischemic. The clinical manifestations are those of pyelonephritis such as dysuria, fever, nausea, vomiting, flank pain. Other potential clinical manifestations include acute renal dysfunction, hyperglycemia, thrombocytopenia, lethargy, acid-base irregularities. EPN is a life-threatening disease associated with septic complications. EPN requires a radiological diagnosis. Computed tomography $(\mathrm{CT})$ is the imaging test of choice to confirm the presence and extent of the parenchymal gas. ${ }^{6}$

\section{Case Report}

A 68-year-old woman was admitted to the medical ward with a one-day history of left lower abdominal pain, vomiting and fever. She had a history of hypertension and type 2 diabetes mellitus, treated with oral anti-diabetic drugs. On examination she presented with fever $\left(39.1^{\circ} \mathrm{C}\right)$, her blood pressure was $160 / 80$ $\mathrm{mm} / \mathrm{Hg}$ and the heart rate was 87 beats per minute. She had left flank pain, accentuated by local palpation. Cardiorespiratory examination was normal. She presented without any focal neurological deficit.

Her blood tests showed renal impairment, decompensated diabetes, a high leukocyte count with a neutrophil segment, high inflammatory markers and a very high pro-calcitonin (Table 1). Urinalysis showed the presence of hyaline cylinders. Urine and blood samples were collected for bacterial culture analysis. A plain abdominal radiograph revealed no pathological findings; a renal ultrasound was performed revealing dilatation of the pelvicalyceal system and upper ureter of the left kidney ( $0.6 \mathrm{~cm}$ diameter). The patient was managed with intravenous fluids and insulin to achieve euglycemia. In suspicion of pyelonephritis, empiric intravenous antibiotics in the form of levofloxacin and meropenem were administered. A plain non-contrast CT (NCCT) scan demonstrated the pres- 
ence of intraparenchymal gas within the left kidney and a dilatation of the ampulla and of the upper ureter (Figure 1). The diagnosis of EPN was made. The admission urine culture later grew E. coli, sensitive to levofloxacin and meropenem, which were continued at the renal dosage. The $24-h$ proteinuria resulted very high; blood culture samples showed no bacterial growth. The patient's clinical condition progressively improved, the abdominal pain improved and a good glycemic control was achieved. A control CT scan was repeated after 8 days of antibiotic therapy and showed no more intraparenchymal gas and the dilatation was not more appreciable. The patient was discharged after a three-week-long hospitalization without fever, with normalized inflammatory markers, and an improved renal function (creatinine $2.9 \mathrm{mg} / \mathrm{dL}$ ); though there was still a nephrotic-range proteinuria.

\section{Discussion}

First described in 1898, EPN is a rare, severe, necrotizing and gas-forming infection of the renal parenchyma and perirenal tissue. The pathogenesis is thought to involve different conditions: the presence of gas forming bacteria, high tissue glucose level, impaired tissue perfusion and a defective immune response. ${ }^{3}$ It deserves special attention because of its life-threatening potential. Underlying poorly controlled diabetes mellitus is present in up to $95 \%$ of the affected patients. ${ }^{2,7}$ The mean age of patients with EPN is 60 years (range $37-83$ years). ${ }^{8}$ Women are affected six times more frequently than men. ${ }^{3}$ The most common clinical manifestations of EPN are those of pyelonephritis such as dysuria, fever, nausea, vomit-

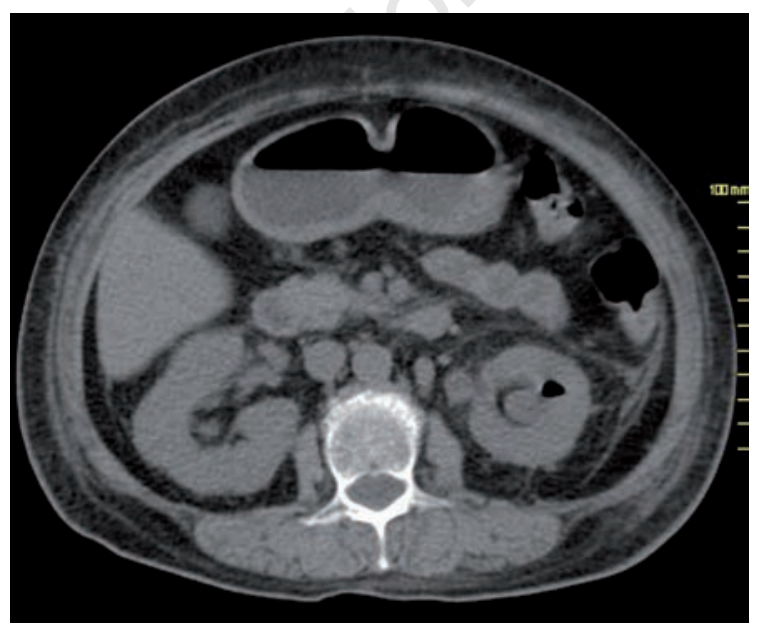

Figure 1. Non-contrast computed tomography of abdomen at admission revealing the presence of gas in the left renal parenchyma, suggestive of emphysematous pyelonephritis. ing, and flank pain. ${ }^{5}$ Thrombocytopenia, acute renal function impairment, disturbance of consciousness and shock are sometimes the initial presentation and are associated with higher mortality. ${ }^{8}$ Also bilateral $\mathrm{EPN}^{3}$ and severe proteinuria ${ }^{8}$ are associated with poor prognosis. The diagnosis of EPN is often delayed because the clinical manifestations are non-specific and not different from the classic symptoms of upper urinary tract infections. ${ }^{9}$ Thus EPN requires a radiological diagnosis. Conventional radiography may demonstrate gas bubbles overlying in the perinephric tissue. Ultrasonography characteristically shows an enlarged kidney containing high-amplitude echoes within renal parenchyma. ${ }^{10} \mathrm{CT}$ is the imaging procedure of choice not only to confirm the presence and extent of parenchymal gas, but also to plane the treatment option. In 2000 Huang and Tseng proposed a radiological classification based on the location of the gas in the kidney (Table 2). ${ }^{8}$ This classification was to show the correlation between the class of EPN and its management. The treatment strategies include medical management (MM) only, percutaneous catheter drainage (PCD) plus MM, MM plus emergency

Table 1. Laboratory findings at admission.

\begin{tabular}{lc}
\hline Laboratory variable & Value \\
\hline $\mathrm{Hb}(\mathrm{g} / \mathrm{dL})$ & 8.7 \\
\hline $\mathrm{WBC} / \mathrm{mm}^{3}$ & $15,900(\mathrm{~N} 87.3 \%)$ \\
\hline $\mathrm{PLT} / \mathrm{mm}^{3}$ & 222,000 \\
\hline Sodium $(\mathrm{mEq} / \mathrm{L})$ & 128 \\
\hline Potassium $(\mathrm{mEq} / \mathrm{L})$ & 3.9 \\
\hline Glycemia $(\mathrm{mg} / \mathrm{dL})$ & 401 \\
\hline HbA1c $(\%)$ & 10.2 \\
\hline Creatinine $(\mathrm{mg} / \mathrm{dL})$ & 4.61 \\
\hline Azotemia $(\mathrm{mg} / \mathrm{dL})$ & 66 \\
\hline C-reactive $\mathrm{protein}(\mathrm{mg} / \mathrm{L})$ & 31.05 \\
\hline Procalcitonin $(\mathrm{ng} / \mathrm{mL})$ & $>200$
\end{tabular}

$\mathrm{Hb}$, hemoglobin; WBC, white blood cells count; PLT, platelets; HbAlc, glycated hemoglobin.

Table 2. Radiological classification of emphysematous pyelonephritis.

\begin{tabular}{ll}
\hline Class 1 & Gas confined to the collecting system \\
\hline Class 2 & Gas confined to the renal parenchyma alone \\
\hline Class 3a & Extension of gas or abscess to the perinephric space \\
\hline Class 3b & Extension of gas or abscess to the pararenal space \\
\hline Class $4 \quad$ Bilateral EPN or EPN in a solitary kidney \\
\hline EPN, emphysematous pyelonephritis. Modified from Huang and Tseng, $2000{ }^{8}$
\end{tabular}


nephrectomy and PCD plus MM plus emergency nephrectomy. ${ }^{3}$ Traditionally, immediate nephrectomy has been considered to be essential to increase the chance of survival because the mortality rate in patients treated with antibiotics alone was around $40 \%{ }^{8}$ Recently, percutaneous drainage has been reported as a kidney-saving and life-saving alternative to surgery. ${ }^{11}$ However there are growing reports of successful medical treatment of EPN. ${ }^{12-15}$ According to these reports, our case could be considered treatable by antibiotics alone partly because of the rapid diagnosis and the adequate therapy provided.

We described the case of a woman affected by diabetes mellitus, presenting with symptoms and signs suggestive of pyelonephritis: dysuria, fever, vomiting and abdominal pain. Moreover we observed renal impairment and nephrotic-range proteinuria, which have usually been considered associated with worse prognosis. An early CT scan of the abdomen revealed the presence of intraparenchymal gas within the left kidney thus leading to the diagnosis of emphysematous pyelonephritis.

Our case is considered class 2 according to the classification of Huang and Tseng, since the gas was confined in the renal parenchymal without extension to the extra-renal space, and could be treated by PCD and MM. On the same day of the diagnosis the medical treatment was started. We empirically chose the antibiotic therapy (levofloxacin and meropenem) on the basis of the bacteria more frequently involved in the pyelonephritis in diabetic patients; we administered intravenous fluid and insulin in order to quickly achieve a good glycemic control. Our patient presented a good clinical response to conservative treatment and had a favorable outcome.

\section{Conclusions}

This case shows the importance of considering the possibility of EPN in patients, particularly those with diabetes, who present with symptoms of pyelonephritis. EPN requires a radiological diagnosis and the prompt diagnosis is fundamental to improve the outcome. Computed tomography is the imaging procedure of choice to confirm the presence and extent of parenchymal gas. However, the management of EPN still remains a controversial issue.

This case is of value because supports the evidence of a successful MM, used alone, in a case of an EPN confined to the renal parenchyma, thanks to an early diagnosis and a promptly started adequate antibiotic treatment.

\section{References}

1. Michaeli J, Mogle P, Perlberg S, et al. Emphysematous pyelonephritis. J Urol 1984;131:203-8.

2. Falagas ME, Alexiou VG, Giannopoulou FP, Siempos II. Risk factors for mortality in patients with emphysematous pyelonephritis: a meta-analysis. J Urol 2007; 178:880-5.

3. Ubee SS, McGlynn L, Fordham M. Emphysematous pyelonephritis. BJU Int 2011;107:1474-8.

4. Tang HJ, Li C, Yen MY, et al. Clinical characteristics of emphysematous pyelonephritis. J Microbiol Immunol Infect 2001;34:125-30.

5. Khaira A, Gupta A, Rana DS, et al. Retrospective analysis of clinical profile prognostic factors and outcomes of 19 patients of emphysematous pyelonephritis. Int Urol Nephrol 2009;41:959-66.

6. Grayson DE, Abbott RM, Levy AD, Sherman PM. Emphysematous infections of the abdomen and pelvis: a pictorial review. Radiographycs 2002;22:543-61.

7. Wan YL, Lee TY, Bullard MJ, Tsai CC. Acute gas-producing bacterial renal infection: correlation between imaging findings and clinical outcome. Radiology 1996;198:433-8.

8. Huang JJ, Tseng CC. Emphysematous pyelonephritis: clinical radiological classification, management, prognosis and pathogenesis. Arch Intern Med 2000;60:797-805.

9. Pontin AR, Barnes RD. Current management of emphysematous pyelonephritis. Nat Rev Urol 2009;6:272-9.

10. Best CD, Terris MK, Tacker JR, Reese JH. Clinical and radiological findings in patients with gas forming renal abcess treated conservatively. J Urol 1999;162:1273-6.

11. Somani BK, Nabi G, Thorpe P, et al. Is percutaneous drainage the new gold standard in the management of emphysematous pyelonephritis? Evidence for a systematic review. J Urol 2008;179:1844-9.

12. Mallet M, Knockaert DC, Oyen RH, et al. Emphysematous pyelonephritis: no longer a surgical disease. Eur J Emerg Med 2002;9:266-9.

13. Shigemura K, Yasufuku T, Yamashita M, et al. Bilateral emphysematous pyelonephritis cured by antibiotics alone: a case and literature review. Jpn J Infect Dis 2009;62:206-8.

14. Bhat RA, Khan I, Khan I, et al. Emphysematous pyelonephritis: outcome with conservative management. Indian J Nephrol 2013;23:444-7.

15. Laway BA, Bhat MA, Bashir MI, et al. Conservative management of emphysematous pyelonephritis. Indian J Endocrinol Metab 2012;16:303-5. 